\title{
La pauvreté, un choix politique au Royaume-Uni
}

\section{Maroussia Raveaud}

\section{(2penEdition}

\section{Journals}

Édition électronique

URL : https://journals.openedition.org/ries/6858

DOI : $10.4000 /$ ries. 6858

ISSN : 2261-4265

\section{Éditeur}

France Education international

\section{Édition imprimée}

Date de publication : 1 décembre 2018

Pagination : 17-19

ISBN : 978-2-85420-620-3

ISSN : 1254-4590

\section{Référence électronique}

Maroussia Raveaud, "La pauvreté, un choix politique au Royaume-Uni », Revue internationale d'éducation de Sèvres [En ligne], 79 | décembre 2018, mis en ligne le 01 décembre 2020, consulté le 25 juin 2021. URL : http://journals.openedition.org/ries/6858 ; DOI : https://doi.org/10.4000/ries.6858

Ce document a été généré automatiquement le 25 juin 2021

(c) Tous droits réservés 


\title{
La pauvreté, un choix politique au Royaume-Uni
}

\author{
Maroussia Raveaud
}

1 Dans la cinquième puissance économique mondiale, abritant la riche et puissante City de Londres, près d'un Britannique sur cinq vit sous le seuil de pauvreté et le taux de pauvreté des enfants pourrait atteindre les $40 \%$. Pour Philip Alston, Rapporteur spécial sur l'extrême pauvreté et les droits de l'Homme à l'ONU, « ce n'est pas seulement une honte, mais une calamité sociale et un désastre économique». Après des rapports qui l'ont mené en Chine, en Arabie Saoudite, aux États-Unis, au Ghana, ce qui le frappe au Royaume-Uni est que "la pauvreté est un choix politique». Si le milieu associatif, des comités parlementaires, organes statistiques indépendants et bien d'autres tirent la sonnette d'alarme, « le gouvernement reste résolument dans le déni » et « les ministres rencontrés insistent sur le fait que tout va bien $»^{1}$.

2 Une mission de douze jours en novembre 2018 a conduit Philip Alston en Angleterre, au Pays de Galles, en Écosse et en Irlande du Nord. L'Australien, professeur en droit international et spécialiste des droits de l'Homme, y a rencontré des jeunes, des personnes âgées, des handicapés, des chômeurs, des sans-abri, des élus, le personnel d'une bibliothèque, d'une école, des bénévoles, des ministres... Ce qu'il a vu et entendu revient, selon lui, à une remise en cause en profondeur de l'État-Providence, qui frappe de plein fouet les plus vulnérables : enfants, mères célibataires, travailleurs précaires. Les réformes des dix dernières années sont justifiées comme une nécessité dans le cadre de la politique d'austérité qui a suivi la crise financière mondiale, ce à quoi s'ajoute l'incertitude économique liée au Brexit. Mais «c'est la mentalité derrière les réformes qui a infligé le plus de misère et causé le plus de dégâts dans le tissu social ». La valorisation de la responsabilité individuelle, la réduction des dépenses publiques et l'insistance sur l'emploi à tout prix ne relèvent pas tant d'une logique économique mais surtout, estime l'auteur, d'un projet idéologique visant à démanteler le contrat social de l'après-guerre.

3 Les coupes budgétaires sont décidées sans se soucier de leur impact humain. «La compassion pour les personnes en souffrance a été remplacée par une approche 
punitive, mesquine et souvent sans pitié ». Les coupes budgétaires sont d'ailleurs loin d'être aussi rentables que prévu car le démantèlement des systèmes de prévention conduit à des situations de crise nécessitant des fonds d'urgence extrêmement coûteux.

4 Les autorités locales britanniques, responsables des services sociaux et d'une partie des établissements scolaires, ont vu leur financement de la part du gouvernement central chuter de $49 \%$ depuis 2010. Le maintien de leurs obligations légales en matière de prise en charge sociale des adultes et de protection de l'enfance s'est fait au détriment des services préventifs et proactifs. Des bibliothèques, centres socio-éducatifs pour l'enfance, fonds de solidarité, etc. ont été les victimes de l'austérité. Sur le terrain, Philip Alston a vu les conséquences des coupes : une augmentation du nombre de sansabri de $60 \%$ depuis 2010 ; le recours aux banques alimentaires a quadruplé depuis 2012 ; même avec un taux de chômage minime (4,1 \% en septembre 2018 contre 7 \% en 2013), le travail ne met pas à l'abri de la pauvreté, du fait des bas salaires, des emplois précaires et des contrats « zéro heures ». Dans les écoles, les budgets moyens ont été amputés de $8 \%$ en termes constants en huit ans, d'après l'Institute for Fiscal Studies. Une grande partie des services de prévention et d'aide aux élèves en difficulté (pastoral care) a disparu. Près des trois quarts des chefs d'établissement pensent ne pas pouvoir équilibrer leur budget dans l'année à venir. Pour Philip Alston, le degré de mobilisation des associations, églises et communautés est celui qu'il associe à une situation de catastrophe naturelle ou d'épidémie.

Pourtant, affirme le Rapporteur aux Nations-Unies, « l'austérité aurait pu épargner les plus pauvres si la volonté politique avait existé ». Mais les choix budgétaires pénalisent les plus démunis et les plus vulnérables : les $20 \%$ des salariés gagnant le moins verront leurs revenus diminuer de $10 \%$ d'ici 2021, tandis que les réformes fiscales ne touchent pas aux revenus des mieux dotés. La Commission à l'égalité et aux droits de l'Homme le confirme. Dans un rapport au Parlement, elle affirme que «le tableau est toujours sombre en Grande-Bretagne, pour ce qui est des conditions de vie des groupes les plus à risque et laissés-pour-compte $»^{2}$. La Commission a passé au crible l'impact des dépenses publiques de 2000 à 2015, et conclu que les choix fiscaux touchent disproportionnellement les catégories vulnérables, ce qui enfreint les conventions internationales des droits de l'Homme. Le contraste entre l'Angleterre et l'Écosse est éclairant : l'Écosse a utilisé sa marge de manœuvre fiscale pour tempérer les inégalités. Ainsi les familles monoparentales ont perdu $19 \%$ de leurs revenus en Angleterre contre $7,6 \%$ en Écosse ${ }^{3}$. Les dépenses publiques doivent chuter de $€ 1500$ par ménage en Angleterre d'ici 2021-22, contre $€ 500$ au Pays de Galles et $€ 200$ en Écosse.

Le gouvernement rejette vivement les conclusions du Rapporteur aux Nations Unies : «Nous sommes en fort désaccord avec cette analyse» (porte-parole du premier ministre); "Nous sommes prêts à travailler avec des experts, mais cette sorte de langage est totalement inappropriée et discrédite une grande partie de ce qu'il avance " (Amber Rudd, ministre de l'emploi). Mais dans une période de crise gouvernementale autour du Brexit et de spéculation sur la longévité de Theresa May à Downing Street, les rapports se succèdent et passent largement inaperçus du grand public. 


\section{NOTES}

1. Un communiqué de presse a été publié le 16 novembre 2018, le rapport ne sera publié que dans quelques mois. Voir : [https://bit.ly/20MeqRy]

2. Equality and Human Rights Commission, Is Britain Fairer? The state of equality and human rights 2018.

3. Voir The Guardian, 28 novembre 2018: [https://bit.ly/2BACBPB].

\section{INDEX}

Index géographique : Royaume-Uni

Mots-clés : pauvreté, politique publique, dépenses publiques

Palabras claves : pobreza, política pública, gasto público

Keywords : poverty, public policy, public expenditure

\section{AUTEUR}

\section{MAROUSSIA RAVEAUD}

Maroussia Raveaud s'intéresse à la socialisation et à la citoyenneté à l'école, privilégiant l'entrée comparative et les approches ethnographiques. Elle a été membre associé à l'Observatoire sociologique du changement (OSC) - CNRS/Sciences-Po et à l'Université de Bristol (Angleterre), et enseignant-chercheur à l'Université du Maine. Actuellement elle travaille avec des familles vulnérables dans un cadre associatif, et explore l'impact du contexte social, économique et familial sur le développement des enfants. Elle est membre associée du comité de rédaction de la Revue internationale d'éducation de Sèvres. Courriel : mraveaud@univ-lemans.fr 